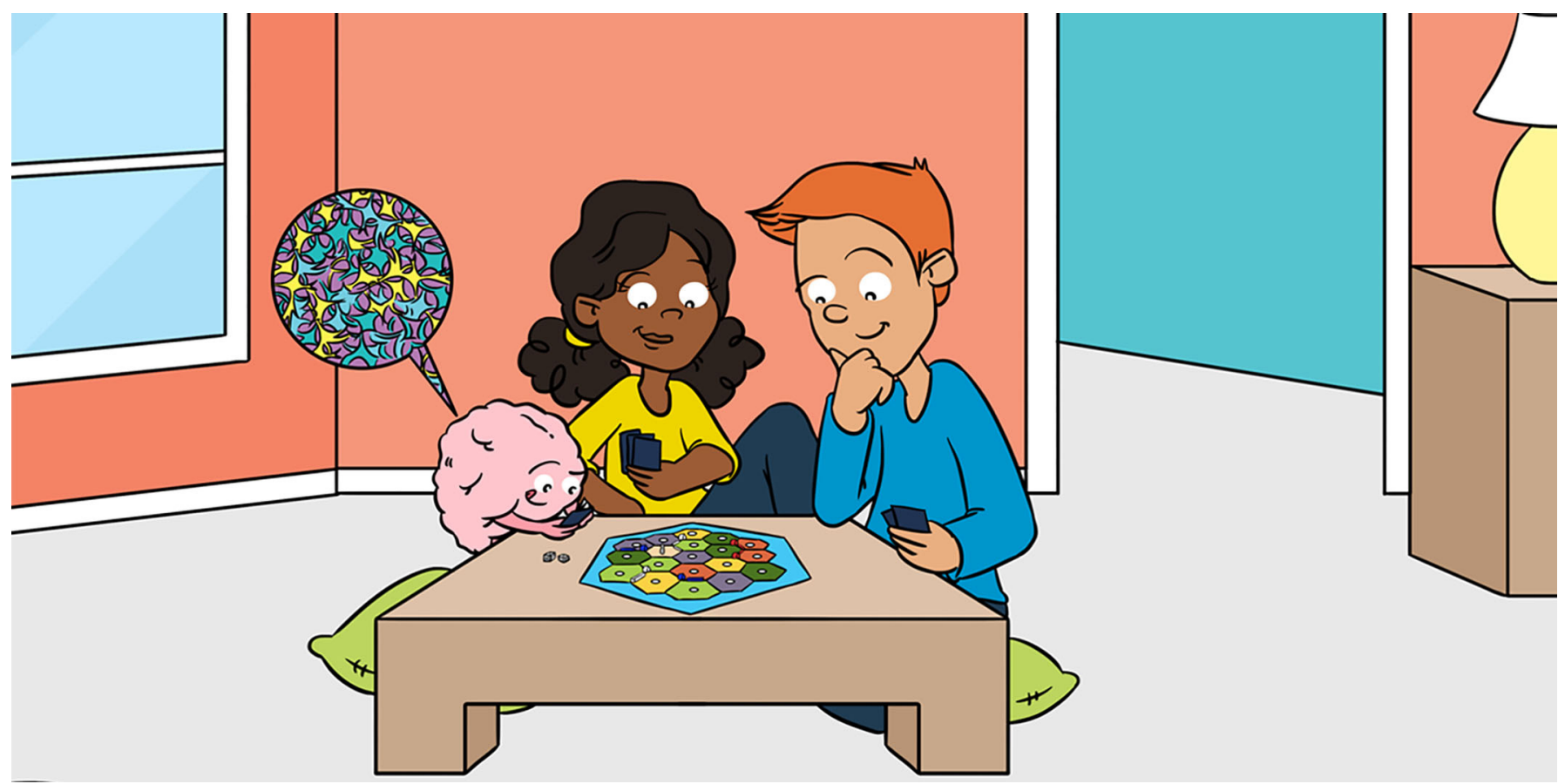

\title{
HOW DOES MY BRAIN COMMUNICATE WITH MY BODY?
}

\author{
Athira Sivadas $^{1^{*}}$ and Kendal Broadie ${ }^{2}$ \\ ${ }^{1}$ Vanderbilt University, Nashville, TN, United States \\ ${ }^{2}$ Department of Biological Sciences, Vanderbilt University, Nashville, TN, United States
}

\section{YOUNG REVIEWER:}

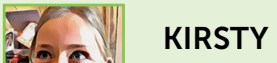

AGE: 8

\section{NEURON}

Electrical cell within the nervous system

specialized to send and receive signals.
You see the ball flying toward you, just five feet away. You sprint to catch it, pumping your legs as hard you can. You catch the ball, gripping it with your fingers. Then suddenly, you hear your mother's voice calling your name. You realize it is time for dinner, so you rush back home. How does all this happen? Of course, you know your brain controls your body, but how does it know what your eyes see, or make your legs run? Your brain is made up of billions of cells called neurons. Your neurons carry information in the form of electrical pulses. Neurons communicate with each other and the rest of your body at special meeting points called synapses.

\section{HOW DO NEURONS SEND AND RECEIVE MESSAGES?}

All of the cells in our body communicate with each other. That is how we are able to do so many things in our daily lives, like eating breakfast and studying for school. In our brain and bodies, neurons communicate with each other by sending messages using a form of 
Figure 1

The structure and function of a nerve cell (a "neuron"). Neurons send and receive electrical signals to communicate with each other in the nervous system and with other types of cells in the body, particularly muscles. At one end, neurons have branch-like projections called dendrites that allow them to receive signals. On neuron sends the signal (the sender neuron) and the other receives it (the receiver neuron). The long "trunk" of the neuron is called the axon, down which the long-distance electrical signal travels. At the end of the axon is a special communication junction called a synapse. The synapse links the end of the axon in one neuron to a dendrite of in a second neuron. There is a very narrow space between the neurons through which a communication signal passes from sender neuron to receiver neuron.

ION

Positively or negatively charged salt particle that move through your cell membranes.

\section{SYNAPSE}

Neuron

communication junction where vesicle fusion releases chemical signals.

\section{NEUROTRANSMITTER}

A chemical signal released at a synapse to bind the next cell's receptor.

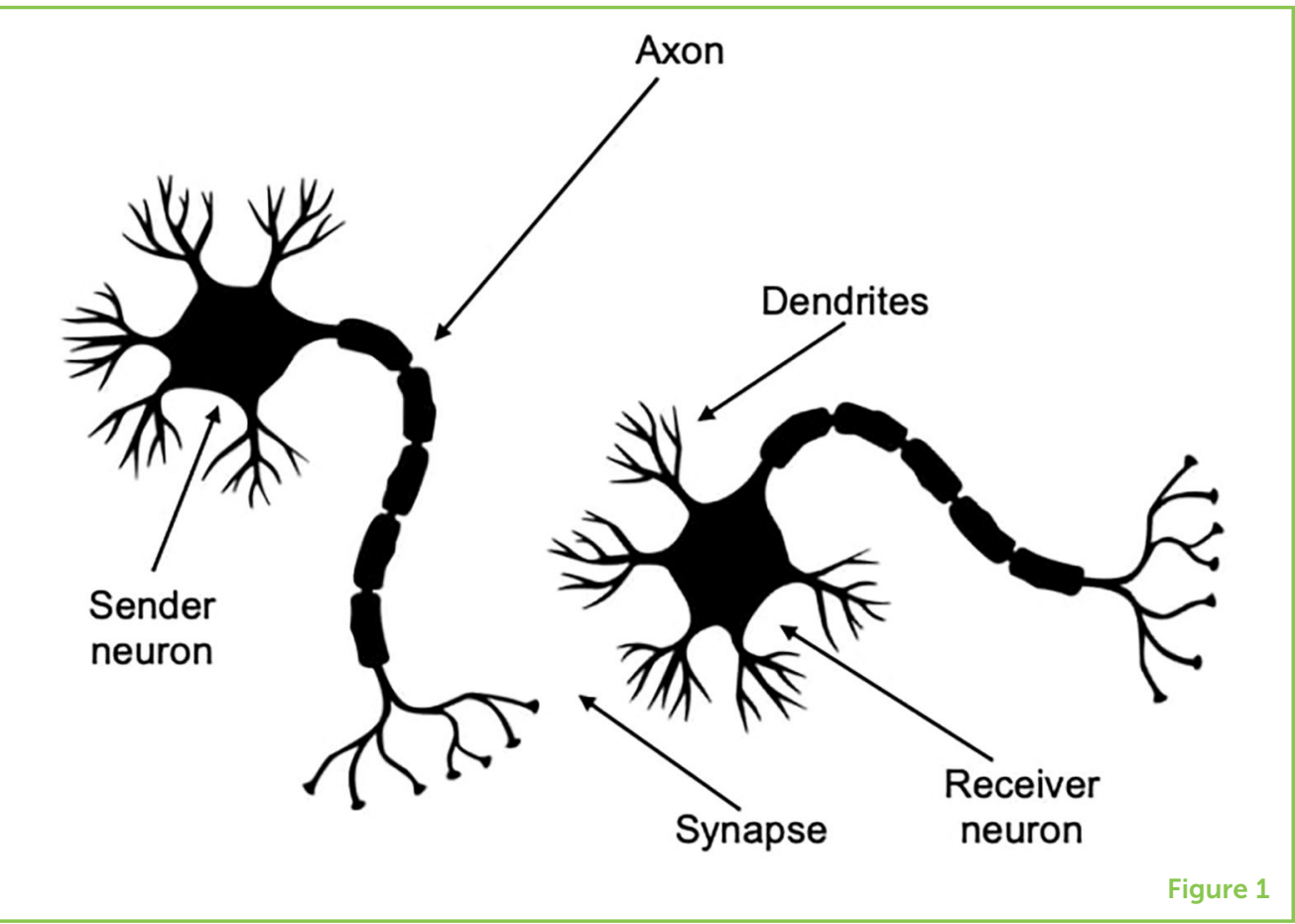

electricity. In neurons, this electricity is created by the flow of charged particles called ions that move across the outer membrane of the cell [1]. The movement of ions carries an electrical wave along the length of the neuron (Figure 1). The neuron has branches (like a tree) called dendrites, which receive signals, and a longer, simpler projection (like a tree trunk), called an axon, which sends signals. Synapses are found at the end of axons. How does the electrical signal jump from one neuron to another? The nerve cell releases chemical signals, called neurotransmitters, which travel across the synapse to another neuron to create a new electrical wave in that cell.

How does an electrical wave travel down a neuron? The neuron's membrane contains tiny channels that can open and shut to allow ions to enter or leave the cell [1]; like the automatic sliding doors at the grocery store. When such a channel opens, it lets ions flood into the cell, carrying electrical charge (Figure 2A). This causes another channel nearby to open, and then the next, such that the electrical wave moves along the cell. To return to rest, a different channel opens more slowly to allow the ions to leave the cell [1]. This ends the electrical wave, setting the stage for the next electrical wave to start the cycle again. The movement of ions continues along the axon to reach the synapse.

\section{HOW DOES A SYNAPSE WORK TO COMMUNICATE BETWEEN CELLS?}

The electrical wave causes the neuron to release small chemical neurotransmitters at the synapse [1], which then travel across to the 
Figure 2

Communication at the synapse. (A) At the synapse, the electrical signal within the neuron is translated into the release of a chemical signal called neurotransmitter. lons flowing into the axon terminal are the signal for vesicles containing neurotransmitter to fuse with the cell membrane to release neurotransmitter. The neurotransmitter then move across to bind receptors in the receiving cell, which open to allow ions to flow into that cell.

(B) An electron microscope image of a neuromuscular junction. In the neuron axon terminal you can see the round vesicles and the synapse mated by the black T-shaped structure. The highly folded muscle membrane contains the receptors, but these are much too small to see, even with an electron microscope. Notice that at the synapse there is an extremely narrow space between the neuron and the muscle cell.

\section{RECEPTOR}

A membrane protein that binds neurotransmitter to allow ion flow into the cell.

NEUROMUSCULAR JUNCTION

The special synapse between a motor neuron and a muscle cell.

\section{ACETYLCHOLINE}

A specific type of neurotransmitter acting at the neuromuscular junction.

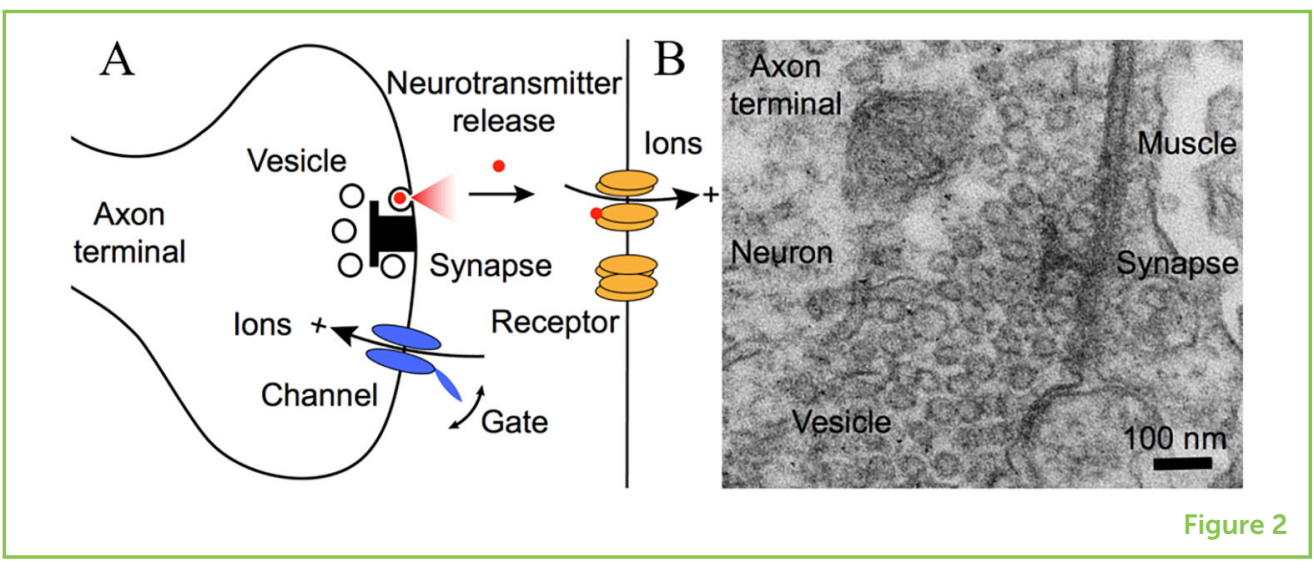

neuron on the other side of the synapse (Figure 2A) [1]. This happens very quickly because the space is very, very narrow (Figure 2B). When the chemical neurotransmitter reaches the receiving cell, it binds to a molecule called a receptor on the membrane of the receiving cell, kind of like a key going into a lock. This causes the ion channels in the receiving cell to open. Ions then flow into the receiving cell and this creates a new electrical message [2].

This is also how our neurons communicate with our muscles, telling us when to move. The synapse between a nerve cell and a muscle cell is called the neuromuscular junction (Figure 2B) [3]. The neurotransmitter released in the neuromuscular junction is called acetylcholine. Just like in neurons, the binding of acetylcholine causes channels to open in the muscle cell, allowing ions to flood into the muscle [3]. This electrical message causes the muscle to contract or shorten. Think about catching a ball: your brain tells a neuron to send an electrical signal to the neuromuscular junction synapse, and this causes neurotransmitter to be released in your finger muscles, so that they contract to catch the ball.

\section{HOW DO SYNAPSES ALLOW ME TO SEE AND HEAR?}

Our senses detect the world around us and transform the many external forms of energy (light, sound, movement) into electrical messages in our neurons. In our eyes, for example, there are light-detecting neurons that respond to the things we see [1]. Some of these special neurons detect colored light (red, green, blue) and some detect just black and white, like an old-fashioned photograph. Light causes channels to open in light-detecting neurons, which sends an electrical message to the synapses of neurons inside your brain (Figure 3) [1]. This information is then processed by the brain to interpret the light images.

For us to hear, sensory receptors in our ears are activated by sound vibrations traveling through the air. These air vibrations move tiny hairs 
Figure 3

Many synapses

communicate within the brain. This image is an artist rendition of neurons in your nervous system. The different colors represent the many different types of neurons, such as those that let you see and hear, or learn and remember. The many projections from each neuron represent the many different synapses that neurons make with each other. Many neurons have thousands of synapses, which allow them to receive and integrate lots of different information, and then relay this information on to other neurons. The nervous system has a property called plasticity, which means that new synapses can form as we learn and strengthen as we make memories. Meanwhile, synapses that we do not use shrink or decrease in number. These changes in the brain can alter how neurons communicate.

\section{PLASTICITY}

The ability of all your synapses to change based on the amount you use them.

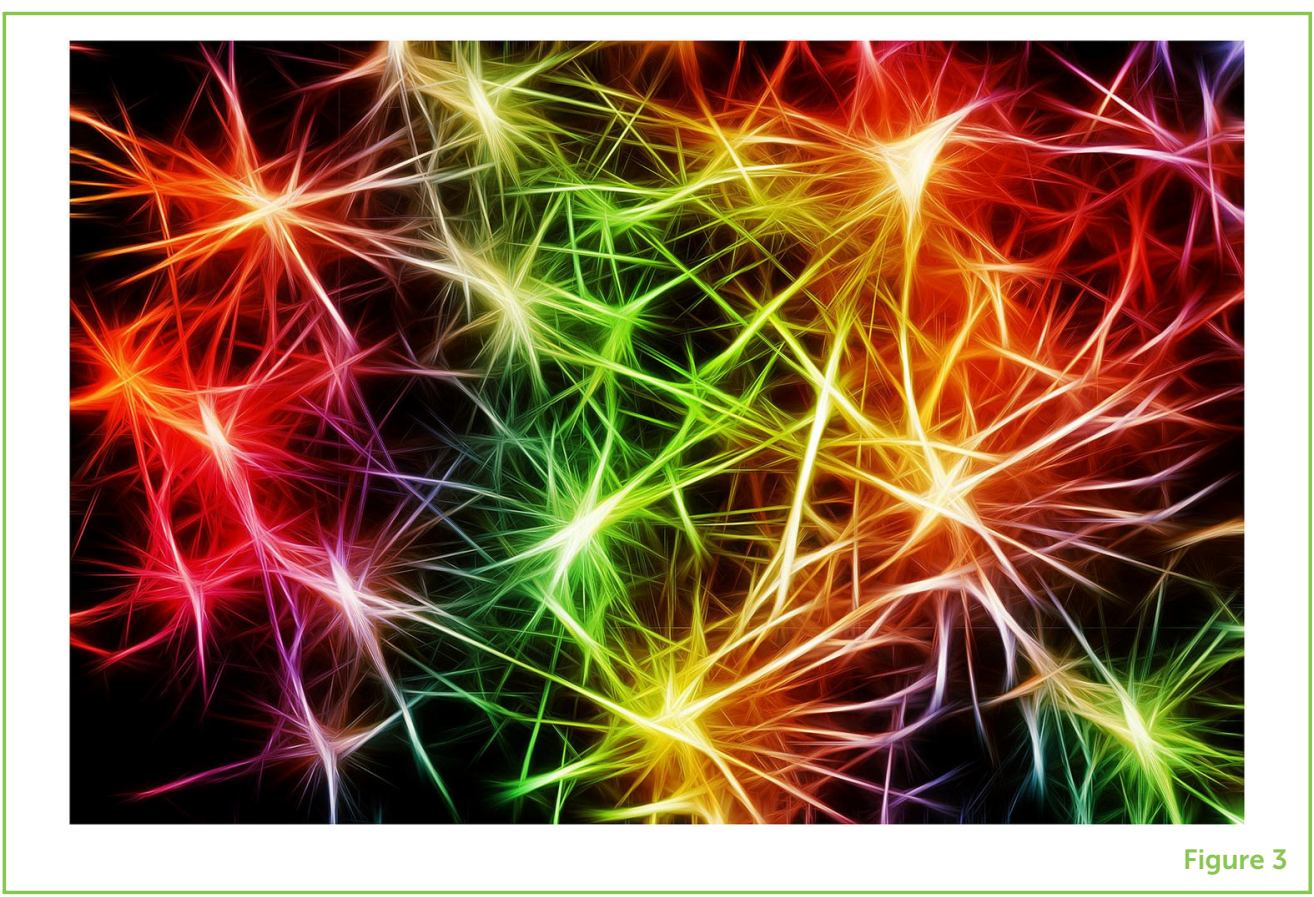

on the ear neurons [1]. This movement opens channels, allowing ions to flood into the neuron and create the electrical message. As a result, neurotransmitters are released at the synapse between the hair cell and a brain neuron. The loudness of the sound depends on how many hairs are bent. Greater bending causes more neurotransmitter to be released at the synapse, which then creates more electrical messages into the brain. These signals travel to brain neurons which interpret them as smells [1].

\section{HOW DO SYNAPSES ALLOW ME TO LEARN AND REMEMBER?}

One of the most important things about our brains is that the number and size of synapses change when we use them. This property of the brain to change in response to what we experience is called plasticity. Plasticity allows us to learn new information and then to remember what we have learned [2]. If we use our synapses a lot, many more can form. If we do not use them as much, synapses can shrink or decrease in number [2]. The strength of communication between synapses can also change depending on how much we use them. If we use them a lot, this can increase the amount of neurotransmitter released, or the number of neurotransmitter receptors on the receiving cell [2]. Synapses are like muscles; they are strengthened by use. If we use our synapses a lot, it can create new, strong synapses that remain in place for many years, even decades [2]. This can help us to form long-term memories. As you know, you can remember things for years; think of your mother's face, or your best friend in the first grade. 


\section{WHAT HAPPENS WHEN SYNAPSES DO NOT WORK PROPERLY?}

Since your synapses are so important for moving, sensing, learning, and remembering, it is easy to see how problems with synapses can cause diseases and disabilities [4-6]. When synapses do not work properly, the brain cannot communicate within itself and with the muscles. Movement disorders often result from problems at the neuromuscular junction [4]. For example, one disease is caused when the neurotransmitter is not cleared out of the synapse. Acetylcholine is released at the neuromuscular junction synapse to cause muscles to contract. If it is not properly removed afterwards, the acetylcholine will continue to bind muscle receptors. This causes improper muscle contraction and movement, and later results in loss of the receptors, and eventually the loss of the muscles [4].

Similarly, problems with synapses can cause losses of sensory perception. Deafness can occur due to problems in synapses of our ear hair cells, causing the overactivation of the nerves in the ear [5]. If our hearing neurons are activated over and over again, it takes a stronger electrical message to continue to activate them. As a result, ear hair cells in people with hearing problems need to feel a louder sound in order to pass on the message to the neurons that travel to the brain [5]. In cases of blindness, light receptor synapse problems can cause light-sensitive cells to disappear completely [6]. Thus, light cannot be turned into electrical signals, and the information is not carried into the brain.

Finally, problems with the plasticity of brain synapses can cause thinking disabilities and autism [1, 2]. Perhaps you know someone with autism spectrum disorder? Autism causes a reduced social interaction and decreased ability to communicate with friends and family. It appears that autism may be caused by problems with plasticity-synapses do not change as much as they should when they are used [1, 2]. Also, new synapses do not form as well as usual and therefore communication between neurons is weakened. Although the causes of autism are still being determined, we know that it is related to our genes.

\section{WHY DO WE NEED TO KNOW ABOUT SYNAPSES?}

So many functions of your body are carried out based on communication between cells that happens at synapses! Right now, as you are reading this, literally trillions of synapses are sending signals whizzing around your brain and into the rest of your body. Neurons are driving movement in your muscles through neuromuscular junction synapses, allowing your eyes to move and your fingers to tap! Your brain synapses are receiving sensory information from your eyes, your ears, and your other senses, and you are using this blizzard of 
information to make the best decisions about what you should do next. Your synapses are changing to allow you to learn and to remember what you learn. Hopefully, your synapses will help the information in this article to stay in your brain as a long-term memory!

\section{REFERENCES}

1. Reece, J. B., Urry, L. A., Cain, M. C., Wasserman, S. A., Minorsky, P. V., and Jackson, R. B. 2014. Campbell Biology. 10th Edn. Glenview, IL:

Pearson Education.

2. Kennedy, M. B. 2016. Synaptic signaling in learning and memory. Cold Spring Harbor Perspect. Biol. 8:1-3. doi: 10.1101/cshperspect.a016824

3. Slater, C. R. 2017. The structure of human neuromuscular junctions: some unanswered molecular questions. Int. J. Mol. Sci. 18:2183. doi: 10.3390/ijms 18102183

4. Merzendorfer, H. 2005. Muscular dystrophies: a novel player. J. Exp. Biol. 208:7. doi: 10.1242/jeb.01388

5. Clarkson, C., Antunes, F. M., and Rubio, M. E. 2016. Conductive hearing loss has long-lasting structural and molecular effects on presynaptic and postsynaptic structures of auditory nerve synapses in the cochlear nucleus. J. Neurosci. 36:10214. doi: 10.1523/JNEUROSCI.0226-16.2016

6. Pottackal, J. 2015. Early events of synapse disassembly in the damaged retina. J. Neurosci. 35:9539. doi: 10.1523/JNEUROSCI.1340-15.2015

SUBMITTED: 06 March 2020; ACCEPTED: 01 September 2020; PUBLISHED ONLINE: 22 October 2020.

EDITED BY: Xi-Nian Zuo, Beijing Normal University, China

CITATION: Sivadas A and Broadie K (2020) How Does My Brain Communicate With My Body? Front. Young Minds 8:540970. doi: 10.3389/frym.2020.540970

CONFLICT OF INTEREST: The authors declare that the research was conducted in the absence of any commercial or financial relationships that could be construed as a potential conflict of interest.

COPYRIGHT @ 2020 Sivadas and Broadie. This is an open-access article distributed under the terms of the Creative Commons Attribution License (CC BY). The use, distribution or reproduction in other forums is permitted, provided the original author(s) and the copyright owner(s) are credited and that the original publication in this journal is cited, in accordance with accepted academic practice. No use, distribution or reproduction is permitted which does not comply with these terms.

\section{YOUNG REVIEWER}

\section{KIRSTY, AGE: 8}

My name is Kirsty and I like maths. I love to read books on my Kindle. I also have a little sister who is 3 years younger than me. 


\section{AUTHORS}

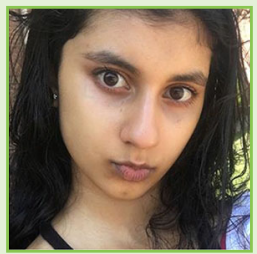

\section{ATHIRA SIVADAS}

I am a pre-med undergraduate student at Vanderbilt University in Nashville, Tennessee. My interests lie in the molecular basis of neurological disorders, such as autism and Down's syndrome. I am especially interested in environmental effects on brain structure and plasticity. In my free time, I volunteer for the American Red Cross. *athira.sivadas@avanderbilt.edu

\section{KENDAL BROADIE}

I am the Stevenson Professor of Neurobiology at Vanderbilt University. I have studied synapses for more than 30 years, including synapse development (synaptogenesis), synapse function (neurotransmission), and use-dependent synapse change (synaptic plasticity). I also model synaptic diseases, such as autism spectrum disorder. 